\title{
Rates and predictors of uncontrolled bronchial asthma in elderly patients from western Romania
}

\author{
This article was published in the following Dove Press journal: \\ Clinical Interventions in Aging \\ 16 June 2015 \\ Number of times this article has been viewed
}

\author{
losif Marincu' \\ Stefan Frent ${ }^{\prime}$ \\ Mirela Cleopatra Tomescu ${ }^{2}$ \\ Stefan Mihaicuta' \\ 'Department of Infectious Diseases, \\ Pulmonology, Epidemiology and \\ Parasitology, ${ }^{2}$ Department of Internal \\ Medicine I, Victor Babes University \\ of Medicine and Pharmacy, Timisoara, \\ Romania
}

Purpose: Bronchial asthma (BA) is a chronic inflammatory disorder of the airways, featuring variable and often reversible airflow limitations. An accurate assessment of BA control is difficult in practice, especially in the elderly, requiring the assessment of several clinical and paraclinical parameters that are influenced not only by asthma, but also by comorbidities. The purpose of this study was to evaluate the predictors of uncontrolled BA in a group of elderly patients from western Romania.

Patients and methods: We retrospectively evaluated 126 elderly patients (aged $\geq 65$ years), who were consecutively evaluated in the Pulmonology Department of Victor Babes Hospital, Timisoara, Romania, between March 2009 and July 2012. We collected demographic data, performed pulmonary function testing and an asthma control test (ACT), and evaluated the level of BA control based on the 2012 Global Initiative for Asthma guidelines. Statistical processing of the data was done using the Epi Info and STATA programs.

Results: In our study group, 36 (29\%) patients were men and 90 (71\%) were women; their mean age was $74.42 \pm 8.32$ years (range: $65-85$ years). A total of $14.28 \%$ of patients were smokers. About $30.15 \%$ of patients had an ACT score $<19,54.76 \%$ had an ACT score $20-24$, and $15.09 \%$ had an ACT of 25. Moreover, 59.52\% had normal spirometry results. Infectious exacerbations were found in $58.73 \%$ of patients. A history of allergies was demonstrated in $48.41 \%$ of patients, $34.12 \%$ had occupational exposure, and $82.53 \%$ of patients were treated with inhaled corticosteroids. Our results showed that $30.15 \%$ of patients had uncontrolled BA. We found six predictive factors for uncontrolled BA: infectious exacerbation, occupational exposure, mixed (obstructive and restrictive) ventilatory dysfunction, persistent airway obstruction on spirometry, duration of disease in months, and current smoking status. Infectious exacerbations, persistent airway obstructions, and occupational exposure were the most powerful predictors.

Conclusion: Elderly patients represent an important group that is at risk for developing uncontrolled BA. Predictors may identify those elderly patients with uncontrolled BA and facilitate early medical interventions.

Keywords: predictors, comorbidities, spirometry, smokers

\section{Introduction}

Asthma is caused by a chronic inflammation of the bronchial tree. The exaggerated response to different triggers induces intermittent airflow obstruction, clinically manifesting as wheezing, paroxysmal dyspnea, cough, and chest compression. Airflow obstruction is often severe, with large variability and reversibility after bronchodilation. ${ }^{1}$

The evaluation of asthma control is difficult. Given the chronic nature of the symptoms, patients have the tendency to underestimate the severity of the disease. For an accurate assessment, guidelines recommend the evaluation of daily and nightly symptoms, quantification of daily activity impairment (at work in adults and at school in children)
Correspondence: Mirela Cleopatra

Tomescu

Department of Internal Medicine I,

Victor Babes University of Medicine and Pharmacy, Bd Revolutiei din $1989 \mathrm{nr} 12$

Timisoara 300024, Romania

Tel +40 722979516

$\mathrm{Fax}+40256220636$

Email tomescu.mirela@umft.ro submit your manuscript | www.dovepress.com

Dovepress

http://dx.doi.org//0.2147/CIA.58314| 
as well as documentation of the number of rescue medication doses per week, the variability of obstruction over time, and the number of exacerbations. Goals of the management of asthma are well defined in the Global Strategy for Asthma Management and Prevention Guidelines. ${ }^{1}$ Control of the symptoms is the main objective, together with achieving normal levels of activity and pulmonary function, ensuring fewer side effects from medication, fewer exacerbations, and decreased mortality rates. ${ }^{2}$ A lack of asthma control leads to decreased quality of life and to increased costs for the medical health system. Asthma in the elderly is underdiagnosed because of less typical presentation, subjective awareness, perception, and attribution of pulmonary symptoms being poor. ${ }^{3}$

Elderly asthmatic patients have worse short- and longterm asthma control when compared with the young adult population. ${ }^{4}$ There is no pathophysiological difference between asthma in the elderly and asthma in the rest of the population. The difference is actually due to drug pharmacokinetics, given the differences in the subject's volume of distribution. $^{5}$

\section{Materials and methods}

Our longitudinal observational study included a population group of 126 elderly patients, evaluated at the Pulmonology Department, Victor Babes Hospital, Timisoara, Romania, from March 2009 to July 2012, with a diagnosis of BA. Diagnosis and treatment of BA were established at a baseline visit by physicians from our department, as based on the definition proposed by the Global Initiative for Asthma Guidelines. ${ }^{1}$ Chronic obstructive pulmonary disease (COPD) or overlapping COPD-asthma were ruled out based on a long history of asthma, a positive bronchodilator test with forced expiratory volume in 1 second $\left(\mathrm{FEV}_{1}\right)$ reversibility of more than $12 \%$, and a $200 \mathrm{~mL}$ increase following $400 \mu \mathrm{g}$ of inhaled salbutamol. ${ }^{1}$

The study was performed in a tertiary referral center with a representative study population, and it featured different BA severities and comorbidities. According to local regulations, patients with chronic diseases need a follow-up visit every 6 months after the initial visit (and as needed thereafter) in order to obtain new recommendations for medical prescriptions from their general practitioner. This study was approved by the "Victor Babes" University of Medicine and Pharmacy Timisoara Ethics Commission.

According to the hospital's policies, all investigated patients provided their informed consent so that their data could be used for scientific purposes. An individual file was completed at each visit, with information obtained about the patient's sex, age, medical and family history, smoking, disease onset, the presence of allergies, occupational exposure to asthma triggers (flour, wood dust, fungi, animal dander, or chemicals), spirometry history, treatment duration, current medication, dosages, and reported compliance. Smoking was quantified as pack-years. Allergy was reported based on the patient's medical history, including previous skin prick testing and/or a specific serum IgE test. Occupational exposure was obtained from the patient's medical history.

We reported on infectious exacerbation, as per the patient's history, including moderate to severe exacerbation and treatment with antibiotics and/or a short course of systemic corticosteroids at unscheduled visits to the general practitioner or emergency departments with hospitalization. At every 6-month follow-up visit, all patients were evaluated for their level of asthma control; they also completed the study file and took an asthma control test (ACT) and spirometry. ACT is a five-question health survey that is completed by the patient; the patients provide information regarding their asthma over the last 4 weeks. Responses to the questions are scored from 1 (the worst) to 5 (the best). An ACT score of less than 19 indicates uncontrolled asthma, a score of 20-24 indicates partially controlled asthma, and a score of 25 is attributed to totally controlled asthma.

Asthma exacerbation was defined as an episode of progressive worsening of symptoms, including shortness of breath, wheezing, cough, and chest tightness, with a marked decrease from baseline in pulmonary function, such as the $\mathrm{FEV}_{1} \cdot{ }^{6}$ Exacerbation was considered when patients reported the use of systemic corticosteroids or a change in asthma health status severe enough to require a visit to the emergency department or lead to a hospital admission. ${ }^{7}$ Exacerbation caused by infections was defined based on the patient's history, and we documented it based on commonly reported respiratory infections, prescriptions from general practitioners, and hospital admission files.

Technicians performed at least three or more acceptable spirometric curves, with repeatability of $150 \mathrm{~mL}$ or less of $\mathrm{FEV}_{1}$. Reversibility was defined as an increase of more than $200 \mathrm{~mL}$ or $12 \%$ of the $\mathrm{FEV}_{1}$ at 30 minutes following the inhalation of $400 \mu \mathrm{g}$ of salbutamol. ${ }^{8}$

\section{Statistical analysis}

We included all patients over the age of 65 years old who had a history of treated asthma. These patients provided their signed informed consent, and they were completely evaluated at 6 months. We excluded new cases of BA, COPD, untreated $\mathrm{BA}$, and those with incomplete patient data information.

Our study is based on a retrospective analysis of the archived patient data from the Clinic of Pulmonology of the 
Victor Babes Hospital in Timisoara, which is the largest center for pulmonary pathology in western Romania. Using univariate analyses, we calculated the odds ratio (OR) and confidence intervals (CI) for the association between the variables. Epi Info version 3.4 and STATA version 9.2 were used for the statistical analysis. Single and multiple linear regressions were used to assess the associations between continuous variables. $P<0.05$ was considered statistically significant.

\section{Results}

In the final analyses, 126 patients met the inclusion criteria. In terms of sex distribution, there were 36 males $(28.57 \%)$ and 90 females $(71.42 \%)$, with a mean age of $74.42 \pm 8.32$ years (range: 65-85 years). The data are summarized in Table 1.

Asthma onset varied widely with a mean value of $96.54 \pm 92.48$ months. Smoking was reported by $14.28 \%$ of patients.

Our results show that only $19(15.07 \%)$ of the enrolled patients had controlled asthma (ACT $=25)$. Most of the patients $(n=69 ; 54.76 \%)$ were identified as having partially controlled BA (ACT =20-24). According to established criteria, 38 (30.15\%) patients with uncontrolled BA (ACT $<19$ ) were detected. The mean duration for achieving asthma control of was $6.49 \pm 3.72$ months. The ACT scores are listed in Table 2.

Exacerbation was found in $58.73 \%$ of the patients, despite the fact that $82.53 \%$ were treated with inhaled corticosteroids (IC); $59.52 \%$ of patients presented with an abnormal spirometry. Different allergies were reported in $48.41 \%$ of individuals, while $34.12 \%$ had previous occupational exposure to asthma triggers. As shown in Table 3, predictors for uncontrolled asthma were as follows: infectious exacerbation, $\mathrm{OR}=3.95$, (95\% CI: 2.11-7.953), $P<0.001$; occupational exposure, OR =2.18, (95\% CI: 1.256-4.452), $P=0.008$; mixed (obstructive and restrictive) ventilatory dysfunction on spirometry, $\mathrm{OR}=1.17$, (95\% CI: $1.021-1.327), P=0.021$, persistent airway obstruction, $\mathrm{OR}=3.78(95 \% \mathrm{CI}: 1.76-7.78)$ $P=0.001$; duration of disease (months), OR $=1.02,(95 \%$ CI: $1.002-1.035) P=0.021$; and smoking, $\mathrm{OR}=0.87(95 \%$ CI: $0.66-1.09), P=0.012$.

Table I Subject information

\begin{tabular}{lll}
\hline Medical history & Number (n) & Percentage (\%) \\
\hline Allergy & 61 & 48.41 \\
Exacerbation & 74 & 58.73 \\
Occupational exposure & 43 & 34.12 \\
IC & 104 & 82.53 \\
Current smoking & 18 & 14.28 \\
\hline
\end{tabular}

Abbreviation: IC, inhaled corticosteroids.
Table 2 ACT scores in the study group

\begin{tabular}{lll}
\hline ACT score (n) & Number $(\mathbf{n})$ & Percentage (\%) \\
\hline 25 & 19 & 15.07 \\
$20-24$ & 69 & 54.76 \\
$<19$ & 38 & 30.15 \\
\hline
\end{tabular}

Abbreviation: ACT, asthma control test.

\section{Discussion}

Asthma is more prevalent in women, as reported in previous published guidelines. ${ }^{9}$ Geriatric asthma has a heterogeneous clinical and functional presentation, with a prevalence rate similar to that in younger age groups. ${ }^{10}$ Elderly patients with asthma have worse asthma control when compared with the young adult population. ${ }^{4}$ The age of asthma onset may help to improve treatment in older adults. ${ }^{11}$

Exacerbation is more common in patients with asthma, even for mild or moderate forms of the disease. ${ }^{5}$ The onset and the severity vary from patient to patient. In the studied population, despite the general treatment with IC in monotherapy or in combination with bronchodilators or leukotriene modifiers, $30.15 \%$ of the patients had uncontrolled asthma, as defined by previous reported guidelines. ${ }^{12}$ In elderly patients with treated asthma, control of the disease is lost during exacerbation; it is also an issue for patients with a history of occupational exposure to asthma triggers and in those with persistent obstruction at pulmonary function testing.

Exacerbation was related to respiratory infections, such as viral or bacterial infections. There is much evidence for the contribution of respiratory infections in asthma. ${ }^{13,14}$ Allergic sensitization plays a role as a host factor in virusinduced wheezing. ${ }^{15}$ Colonization of the bronchial tree with Chlamydia pneumoniae or Mycoplasma pneumoniae increases the risk of asthma exacerbation. ${ }^{16}$ Persistent obstruction is related to an overlap of asthma with COPD. ${ }^{17}$ Severe asthma exacerbation requires admission to a hospital, increases the cost of treatment, and can be deadly. ${ }^{6}$

Occupational exposure can trigger asthma exacerbation in asthmatic workers, or it can induce asthma in a previously healthy worker. ${ }^{18}$ The high percentage of occupational exposure in our population can be explained by the significant recent development of modern industries in western Romania (ie, the prevalence of electronics, tire production, technical gases, chemical and electrotechnical industry units, the production of auto parts, wiring molds for vehicles, the food industry, mobile phones, washing and cleaning products, meat processors, as well as petrochemical industries). ${ }^{19}$

Our results show the importance of an acute event, as caused by infections or allergy, in the lack of asthma control in elderly patients. A history of occupational exposure makes 
Table 3 Statistical analysis of the predictors for BA control

\begin{tabular}{|c|c|c|c|c|}
\hline Predictor & OR & SE & P-value & $95 \% \mathrm{Cl}$ \\
\hline Infectious exacerbation & 3.95 & 1.357 & $<0.001$ & $2.11-7.953$ \\
\hline Occupational history & 2.18 & 0.780 & 0.008 & $1.256-4.452$ \\
\hline Mixed (obstructive and restrictive) ventilatory dysfunction in spirometry & 1.17 & 0.075 & 0.021 & $1.021-1.327$ \\
\hline Persistent airway obstruction in spirometry & 3.78 & $\mathrm{I} .27 \mathrm{I}$ & 0.001 & I.76-7.78 \\
\hline History of BA onset (months) & 1.02 & 0.008 & 0.021 & $1.002-1.035$ \\
\hline Current smoking status & 0.87 & 0.007 & 0.012 & $0.66-1.09$ \\
\hline
\end{tabular}

Note: Significance was determined by a $P$-value of $<0.05$.

Abbreviations: $\mathrm{BA}$, bronchial asthma; OR, odds ratio; SE, standard error; $\mathrm{Cl}$, confidence interval.

this population more vulnerable. Our results are concordant with those reported by Patel et al..$^{20}$ Their study also demonstrated that elderly patients are a high-risk population subgroup for poorly controlled asthma (regression coefficient: 0.09 [95\% CI: $0.01-0.17$ ] for each decade).

\section{Conclusion}

Uncontrolled BA is costly in terms of health care resources, decreased work productivity, and frequent hospitalizations. Through low resistance to respiratory infections, allergy history, and active smoking, elderly patients represent a high-risk population group for poorly controlled asthma. Our study shows that $30 \%$ of the investigated patients had uncontrolled asthma, despite receiving the correct treatment of IC.

Exacerbation infections, a history of occupational exposure, and persistent airway obstruction were the most important predictors for uncontrolled BA. These predictors should be included in surveillance and monitoring program for elderly patients with asthma. These predictors may identify patients with uncontrolled BA and allow for the early medical interventions. Correct and efficient management of these patients would have a positive impact on the patients' quality of life, and it would also reduce costs for the health care system.

\section{Acknowledgments}

English-language editing of this manuscript was provided by Journal Prep.

\section{Disclosure}

The authors report no conflicts of interest in this work.

\section{References}

1. Global Strategy for Asthma Management and Prevention. Global Initiative for Asthma (GINA) 2012. Available from: http://www.ginasthma. org. Accessed May 21, 2015.

2. Bateman ED, Bousquet J, Keech ML, Busse WW, Clark TJ, Pedersen SE. The correlation between asthma control and health status: the GOAL study. Eur Respir J. 2007;29(1):56-62.
3. Burrows B, Lebowitz MD, Barbee RA, et al. Findings before diagnoses of asthma among the elderly in a longitudinal study of a general population sample. J Allergy Clin Immunol. 1991;88:870-877.

4. Talreja N, Baptist AP. Effect of age on asthma control: results from the National Asthma Survey. Ann Allergy Asthma Immunol. 2011;106(1): 24-29.

5. Saetta M, Turato G. Airway pathology in asthma. Eur Respir J Suppl. 2001;34:18s-23s.

6. Schatz M, Sorkness CA, Li JT, et al. Asthma control test: reliability, validity, and responsiveness in patients not previously followed by asthma specialists. J Allergy Clin Immunol. 2006;117:549-556.

7. Tattersfield AE, Postma DS, Barnes PJ, et al. Exacerbations of asthma: a descriptive study of 425 severe exacerbations. The FACET International Study Group. Am J Respir Crit Care Med. 1999;160:594-599.

8. Miller MR, Hankinson J, BrusascoV, et al. Standardization of spirometry. Eur Respir J. 2005;26:319-338.

9. Reddy AP, Gupta MR. Management of asthma: the current US and European guidelines. Adv Exp Med Biol. 2014;795:81-103.

10. Scichilone N, Pedone C, Battaglia S, Sorino C, Bellia V. Diagnosis and management of asthma in the elderly. Eur J Intern Med. 2014;25: 336-342.

11. Baptist AP, Ross, Clark NM. Older adults with asthma: does age of asthma onset make a difference? J Asthma. 2013;50:836-841.

12. O'Byrne PM, Barnes PJ, Rodriguez-Roisin R, et al. Low dose inhaled budesonide and formoterol in mild persistent asthma: the OPTIMA randomized trial. Am J Respir Crit Care Med. 2001;164: 1392-1397.

13. Kusel MM, de Klerk NH, Kebadze T, et al. Early-life respiratory viral infections, atopic sensitization, and risk of subsequent development of persistent asthma. J Allergy Clin Immunol. 2007;119:1105-1110.

14. Johnston SL, Pattemore PK, Sanderson G, et al. The relationship between upper respiratory infections and hospital admissions for asthma: a timetrend analysis. Am J Respir Crit Care Med. 1996;154:654-660.

15. Langley SJ, Goldthorpe S, Craven M, Woodcock A, Custovic A. Relationship between exposure to domestic allergens and bronchial hyper responsiveness in non-sensitized, atopic asthmatic subjects. Thorax. 2005;60(1):17-21.

16. Sutherland ER, Brandorff JM, Martin RJ. Atypical bacterial pneumonia and asthma risk. J Asthma. 2004;41:863-868.

17. Papaiwannou A, Zarogoulidis P, Porpodis K, et al. Asthma-chronic obstructive pulmonary disease overlap syndrome (ACOS): current literature review. J Thorac Dis. 2014;6(Suppl 1):S146-S151.

18. Baur X, Sigsgaard T, Aasen TB, et al; on behalf of the ERS Task Force on the Management of Work-related Asthma. Guidelines for the management of work-related asthma. Eur Respir J. 2012;39: 529-545.

19. Ministry of Health. The study of occupational diseases in Romania. 2011;16-19. Available from: http://www.asparad.ro/Statistica/BOLI PROFESIONALE 2011.pdf. Accessed June 9, 2015. Romanian.

20. Patel M, Pilcher J, Reddel HK, et al. Predictors of severe exacerbations, poor asthma control, and $\beta$-agonist overuse for patients with asthma. J Allergy Clin Immunol. 2014;2(6):751-758.e1. 


\section{Publish your work in this journal}

Clinical Interventions in Aging is an international, peer-reviewed journal focusing on evidence-based reports on the value or lack thereof of treatments intended to prevent or delay the onset of maladaptive correlates of aging in human beings. This journal is indexed on PubMed Central, MedLine,
Dovepress

CAS, Scopus and the Elsevier Bibliographic databases. The manuscript management system is completely online and includes a very quick and fair peer-review system, which is all easy to use. Visit http://www.dovepress. $\mathrm{com} /$ testimonials.php to read real quotes from published authors. 